\title{
Constant wind regimes during the Last Glacial Maximum and early Holocene: evidence from Little Llangothlin Lagoon, New England Tablelands, eastern Australia
}

\author{
James Shulmeister ${ }^{1}$, Justine Kemp ${ }^{2}$, Kathryn E. Fitzsimmons ${ }^{3}$, and Allen Gontz ${ }^{4, a}$ \\ ${ }^{1}$ School of Geography, Planning and Environmental Management, University of Queensland, St. Lucia 4072, Queensland, \\ Australia \\ ${ }^{2}$ Australian Rivers Institute, Griffith University, Nathan 4111, Queensland, Australia \\ ${ }^{3}$ Department of Human Evolution, Max Planck Institute for Evolutionary Anthropology, Deutscher Platz 6, 04103 Leipzig, \\ Germany \\ ${ }^{4}$ School for the Environment, University of Massachusetts Boston, Boston, MA 02125, USA \\ ${ }^{a}$ current address: Department of Geological Sciences, San Diego State University, San Diego, CA 92182, USA
}

Correspondence to: James Shulmeister (james.shulmeister@uq.edu.au)

Received: 24 March 2016 - Published in Clim. Past Discuss.: 6 April 2016

Accepted: 2 June 2016 - Published: 5 July 2016

\begin{abstract}
Here we present the results of a multi-proxy investigation - integrating geomorphology, ground-penetrating radar, and luminescence dating - of a high-elevation lunette and beach berm in northern New South Wales, eastern Australia. The lunette occurs on the eastern shore of Little Llangothlin Lagoon and provides evidence for a lake high stand combined with persistent westerly winds at the Last Glacial Maximum (LGM - centring on $21.5 \mathrm{ka}$ ) and during the early Holocene (ca. 9 and $6 \mathrm{ka}$ ). The reconstructed atmospheric circulation is similar to the present-day conditions, and we infer no significant changes in circulation at those times, as compared to the present day. Our results suggest that the Southern Hemisphere westerlies were minimally displaced in this sector of Australasia during the latter part of the last ice age. Our observations also support evidence for a more positive water balance at the LGM and early Holocene in this part of the Australian sub-tropics.
\end{abstract}

\section{Introduction}

The temperate-latitude westerly wind system influences the southern half of the Australian continent and dictates not only this region's climate but also the formation and response of its landscape systems. It plays an important role in the delivery of winter rainfall to the southern half of Australia. Un- derstanding the history of the westerlies in the Australasian region is therefore important for understanding the climate and environmental history of eastern Australia (Shulmeister et al., 2004; Fletcher and Moreno, 2012; Lorrey et al., 2012). In addition, changes in the Southern Hemisphere westerlies are inferred to modulate global atmospheric carbon dioxide concentrations and potentially trigger global climate changes (e.g. Denton et al., 2010).

Here we investigate past wind regime changes in eastern Australia as reflected in the shoreline marginal landforms of Little Llangothlin Lagoon (LLL). LLL is a presently shallow lake which sits at $30^{\circ} \mathrm{S}\left(30^{\circ} 5^{\prime} 9^{\prime \prime} \mathrm{S}, 151^{\circ} 46^{\prime} 53^{\prime \prime} \mathrm{E}\right)$ in northern New South Wales. It lies close to the present-day northern boundary of the winter westerlies, therefore providing an excellent opportunity to investigate long-term changes in prevailing wind direction and intensity. The lagoon has a lunette (transverse shoreline dune) on its eastern shoreline and a possible beach berm on its south-eastern margin. These landforms reflect aeolian and wave-driven transport and deposition of sediments; they consequently also provide indicators for the orientation of prevailing wind directions and intensity at the time of sediment deposition (Bowler, 1973, 1983, 1986). In this study we undertook luminescence dating, combined with geomorphic and stratigraphic investiga- 


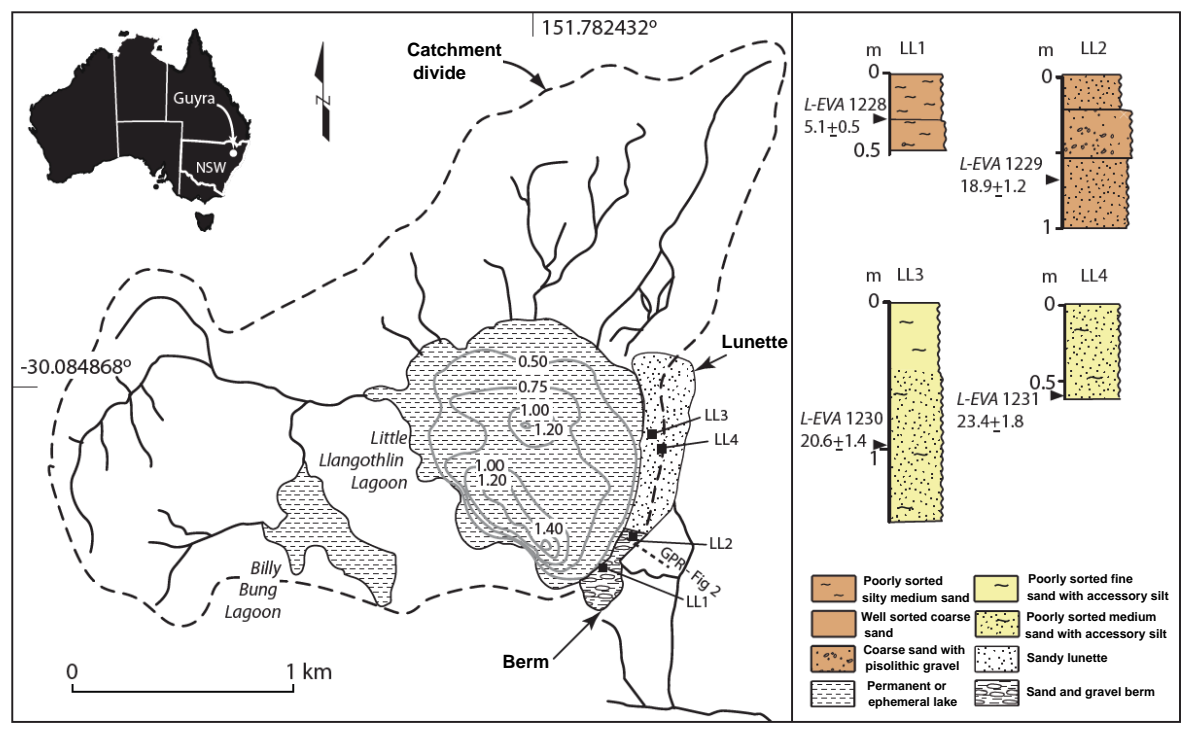

Figure 1. Geomorphology and sediments at Little Llangothlin Lagoon ( $\left.30^{\circ} 5^{\prime} 9^{\prime \prime} \mathrm{S}, 151^{\circ} 46^{\prime} 53^{\prime \prime} \mathrm{E}\right), 18 \mathrm{~km}$ NE of Guyra, NSW, showing the locations of GPR transects, sediment cores (right), and the position of OSL samples.

tions, to reconstruct past periods of westerly, and possible north-westerly, prevailing wind flow in this region.

The endorheic LLL basin was formed in gently undulating tableland comprising Tertiary basalt flows at approximately $1300 \mathrm{~m}$ above mean sea level (a.m.s.l.). The western shoreline of LLL is dominated by a low ridge of basalt, which rises $30 \mathrm{~m}$ above the lake (Fig. 1). On the eastern side of the basin, the lake is bound by a low hill of granite that forms part of the New England Batholith (Shaw and Flood, 1981). The lagoon covers an area of $1.2 \mathrm{~km}^{2}$ and has a catchment of $3.2 \mathrm{~km}^{2}$. LLL is a shallow, roughly circular permanent lake with a maximum depth of $2 \mathrm{~m}$ that shallows during droughts, which in this part of Australia are often associated with El Niño years. As far as we can determine, the lake has never dried out fully in post-European settlement times (Woodward et al., 2014b). Another, smaller, lake (Billy Bung Lagoon) lies ca. $500 \mathrm{~m}$ to the south-west of LLL and is separated from the main lake by the low basalt ridge.

The origin of the New England "lagoons" is cryptic. Conraeds (1989) showed that they were associated with former drainage lines that were occupied by basalt flows. He suggested that uneven infilling of former valleys by basalt during the Tertiary produced shallow depressions where the shallow lakes and swamps, locally called lagoons, formed. Similar lakes have been described elsewhere along the tablelands of the Great Dividing Range, and Ollier (1979) suggested a tectonic origin for these features, proposing that uplift of the Eastern Highlands caused back tilting on many streams. Other authors such as Bell et al. (2008) have suggested a deflationary origin, where intense weathering occurred as a result of wetting and drying of the basalt. The mechanisms are not incompatible, and deflation may have enhanced and maintained the basins, which were created by back tilting.

Many of these upland lakes have lunettes on their eastern margins (sensu Bowler, 1976). These are transverse crescentic ridges dominated by wave action and shoreline drift, with coarse-textured wave-built ridges on downwind margins (Bowler, 1986). Their regular outline reflects the influence of strong wave action, while the aeolian deflation of sands from the beach forms foreshore dunes with an orientation consistent with the winter wind resultant vector (Bowler, 1971). The proportion of clay and silt in lunettes increases during periods of shoreline regression and is derived from efflorescence and pelletisation of saline lacustrine sediments on the drying lake floor. Salt concentration in upland lakes tends to be weaker owing to groundwater seepage, restricting the preparation of pelletal clays for deflation and producing dominantly sandy lunettes.

The catchment is fed by summer rainfall (mean annual rainfall $=880 \mathrm{~mm}$ ) and has a theoretical net annual moisture balance deficit of ca. $400 \mathrm{~mm}$ (Woodward et al., 2014a). The regional vegetation is dominated by montane open eucalypt woodland, while the lagoon itself contains extensive beds of tall spike rush (Eleocharis sphacelata) and the water plant Potamogeton tricarinatus in the deeper parts of the basin. Other swamp plants, including Carex gaudichaudiana, are dominant in the surrounding wet margins of the lagoon.

The lagoon has been intensively investigated from a palaeoecological and environmental viewpoint because it is a major bird reserve as well as a Ramsar wetland. Furthermore, the site has been identified as a location of exceptional soil erosion since European settlement (Gale et al., 1995; Gale and Haworth, 2005), although this has recently been chal- 
lenged (Woodward et al., 2011). The site has more recently become a focus for work due to inferred changes to basin hydrology in response to tree clearance during European settlement of the New England Tablelands (Woodward et al., 2014a). There has also been some investigation of the archaeological history of the lagoon suggesting that landscapes such as these provided relatively rich resources for Aboriginal people and that New England lagoons became the foci for ceremonial activities, although the degree to which hydrological conditions influenced human activity remains poorly understood since chronological control for the pre-European period has so far been lacking (Beck et al., 2015).

This paper examines the geomorphic context of shoreline features on the western and southern margins of the lagoon and focuses on the history of lake-margin sediment deposition to reconstruct the climatic circulation from the Last Glacial Maximum (LGM) into the Holocene.

\section{Materials and methods}

\subsection{Field investigations}

Transects across an apparent beach berm and the lunette were surveyed using a MALA ProEx ground-penetrating radar (GPR) system with a $500 \mathrm{MHz}$ antenna and integrated high-resolution GPS. The GPR data were collected in transects forming a rough grid parallel and perpendicular to the trend of hypothesised beach and lunette landforms. The GPR was hand-dragged at a speed of $\sim 4 \mathrm{kph}$ and fired using time firing at a rate of $10 \mathrm{~Hz}$, resulting in an average along-track resolution of 0.11 and $0.07 \mathrm{~m}$ vertical resolution, based on a centre frequency of $500 \mathrm{MHz}$. After acquisition, radar data were processed using GPR-SLICE software (DC drift; user-defined signal gain; bandpass lo $=350 \mathrm{MHz}$, hi $=650 \mathrm{MHz}$; background removal). Profiles were topographically corrected using elevation data from the GPS system and spot-checked using known elevations. While absolute topography was not reliable, relative elevation was consistently reproducible. Individual profiles were converted to depthdistance using the published radar velocity for wet sands of $0.07 \mathrm{~m} \mathrm{~ns}^{-1}$ in the beach ridges and dry sands of $0.12 \mathrm{~m} \mathrm{~ns}^{-1}$ in the lunette (Neal, 2004). Depth-distance profiles were used to evaluate sediment thickness and observe true geometry of radar reflectors.

The sub-surface sediments were logged using a hand auger to a depth of between 0.6 and $1.2 \mathrm{~m}$, depending on subsurface conditions. Sub-samples were collected for grain size analyses. In addition, gravels from the sand and gravel barrier were treated with $\mathrm{HCl}$ for $12 \mathrm{~h}$ in order to identify weathering products such as manganese-iron pisoliths. Four samples were collected for optically stimulated luminescence (OSL) dating using steel tubes, wrapped in black plastic, and transported to the Max Planck Institute for Evolutionary Anthropology in Leipzig for analysis.

\subsection{OSL dating - equivalent-dose measurements}

Sample preparation and measurement for OSL dating were undertaken in the luminescence dating laboratory of the Department of Human Evolution, Max Planck Institute for Evolutionary Anthropology in Leipzig. The OSL samples were prepared under subdued red light using published methods (Fitzsimmons et al., 2014). This involved sieving, applying $\mathrm{HCl}$ acid and hydrogen peroxide digestion to remove carbonates and organic matter respectively; and isolating pure, 180 $212 \mu \mathrm{m}$ quartz grains. The outer $\sim 10 \mu \mathrm{m}$ alpha-irradiated rind of each grain was removed by etching in hydrofluoric acid, and the sample was then subjected to a final sieve to remove finer fragments which had broken off during etching. The quartz grains were then prepared as small aliquots (18 discs; $1 \mathrm{~mm}$ diameter) for preheat testing and as single grains (600 grains; six single-grain discs) for equivalent-dose $\left(D_{\mathrm{e}}\right)$ measurement.

$D_{\mathrm{e}}$ measurements were undertaken using an automated Risø TL-DA-15 equipped with blue-light-emitting diodes (for preheat and initial dose estimate testing) and a TLDA-20 reader with a single-grain attachment containing a green laser emitting at $532 \mathrm{~nm}$, for light stimulation of single aliquots and single grains respectively (Botter-Jensen et al., 2000). Irradiation was provided by calibrated ${ }^{90} \mathrm{Sr} /{ }^{90} \mathrm{Y}$ beta sources. Equivalent doses were determined on single grains using the single aliquot regenerative dose (SAR) protocol of Murray and Wintle $(2000,2003)$. Preheat temperatures of $260^{\circ} \mathrm{C}$ were chosen based on the results of the preheat plateau tests (Fig. S2 in the Supplement) for the natural and regenerative doses, with a preheat temperature of $220^{\circ} \mathrm{C}$ for the test doses $(0.94 \mathrm{Gyr})$.

Individual grains were analysed for their suitability for OSL dating based on the selection criteria of Jacobs and Roberts (2007). The single-grain dose distributions of all samples are $>40 \%$ overdispersed with complex dose populations (Table S1 in the Supplement), and therefore the finite mixture model (FMM) was used to identify dose populations (Galbraith and Green, 1990). The OSL dating results are summarised in Table 1. Equivalent-dose distributions for the four samples are shown as radial plots, with the FMMderived dose populations highlighted, in Fig. 3.

\subsection{OSL dating - dose rate calculations}

Uranium, thorium, and potassium $\left({ }^{40} \mathrm{~K}\right)$ activities were measured in the "Felsenkeller" laboratory at VKTA Rossendorf in Dresden, Germany, using low-level gamma-ray spectrometry. Dose rates were calculated using the conversion factors of Stokes et al. (2003) with $\beta$-attenuation factors taken from Mejdahl (1979). Beta counting was based on $1 \mathrm{~g}$ homogenised sub-samples and used for the beta component of the dose rate. Measured water contents ranged from 5 to $10 \%$, and these values were used for all samples. Cosmic dose rates were calculated from Prescott and Hutton (1994). 
(a)
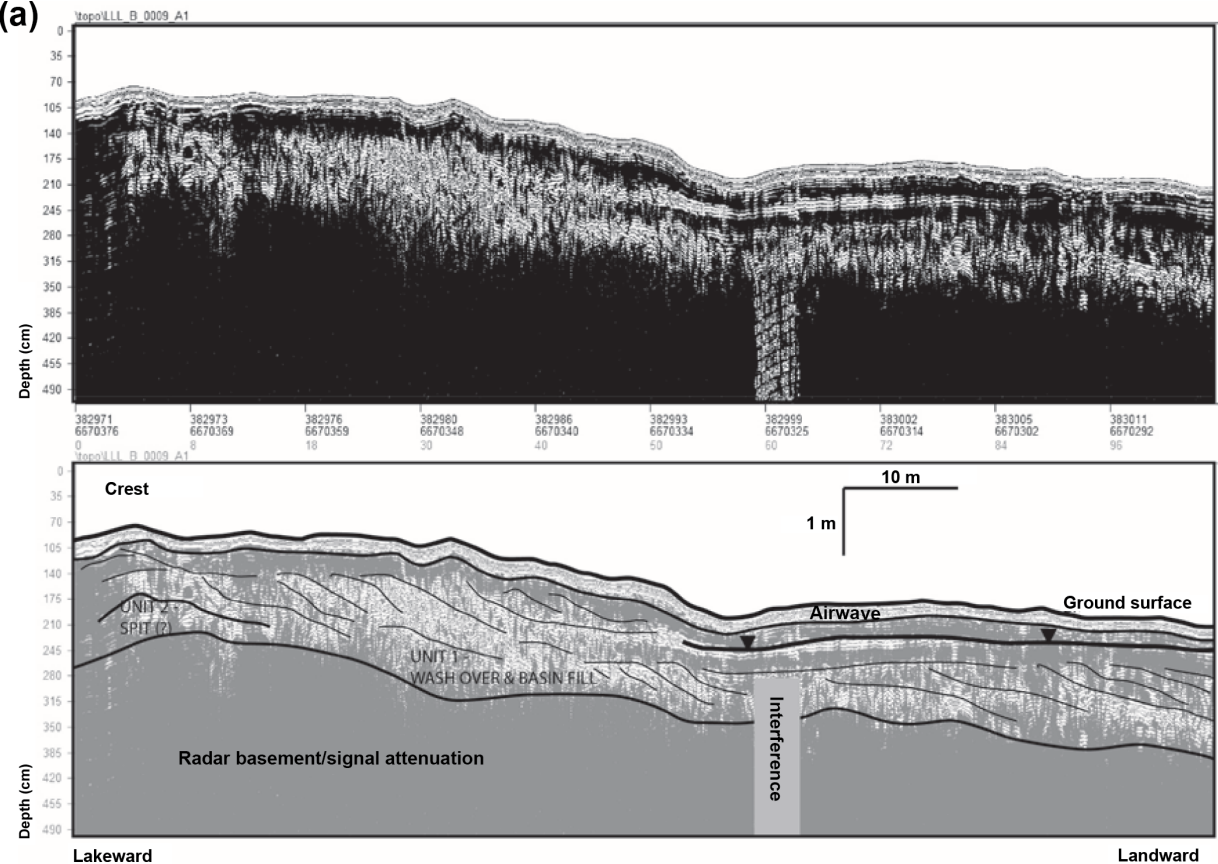

(b)
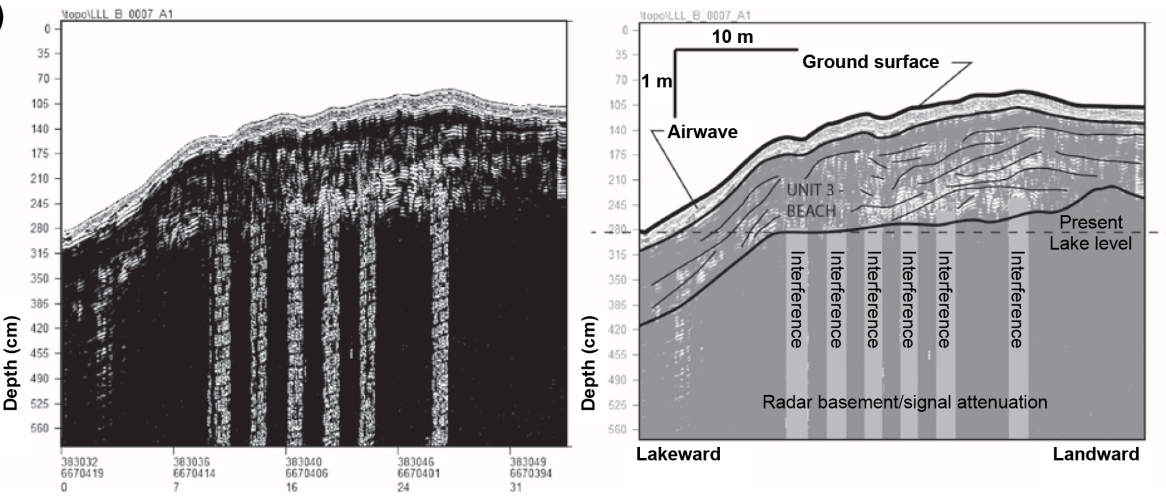

Lakeward

Landward

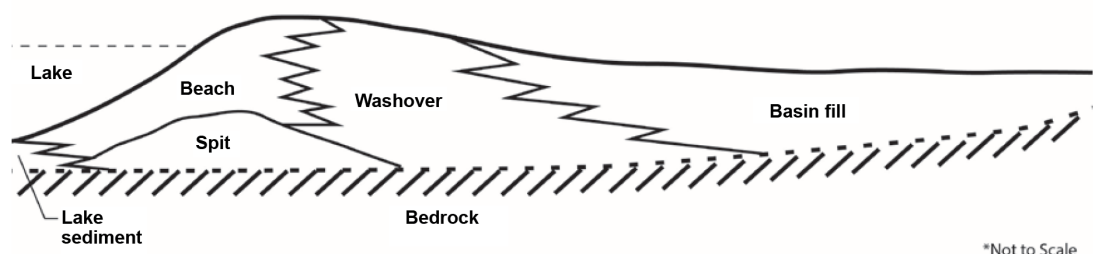

Figure 2. (a) GPR transects over the "berm". See Fig. 1 for location of transect. GPR line A7 was acquired perpendicular to the shoreline starting just lakeward of the highest point on the berm. Internal structures are characteristic of an interfingering beach-wash-over-basin fill sequence over a spit complex. Upper panel, raw data; lower panel, interpretation. (b) GPR line A9 was acquired from the lake shore to the highest point on the berm. Internal structures show characteristics of a beach environment over a spit complex. Top left panel, raw data; top right panel, interpretation. The lower panel shows a conceptual model based on composite GPR profiles suggesting a lower lake facies with spit facies underlying beach, wash-over, and basin fill facies. 
Table 1. Equivalent dose $\left(D_{\mathrm{e}}\right)$, dose rate data, and OSL age estimates for Little Llangothlin Lagoon. Dose rates are listed as attenuated based on published factors (Stokes et al., 2003; Mejdahl, 1979).

\begin{tabular}{|c|c|c|c|c|c|c|c|c|c|}
\hline Sample & $D_{\mathrm{e}}(\mathrm{Gyr})$ & $K(\%)$ & Th (ppm) & $U(\mathrm{ppm})$ & $\begin{array}{l}\text { Beta dose } \\
\text { rate }\left(\mathrm{Gy} \mathrm{ka}^{-1}\right)\end{array}$ & $\begin{array}{l}\text { Cosmic dose } \\
\text { rate }\left(\mathrm{Gy} \mathrm{ka}^{-1}\right)\end{array}$ & $\begin{array}{l}\text { Water } \\
\text { content }(\%)\end{array}$ & $\begin{array}{l}\text { Total dose } \\
\text { rate }\left(\mathrm{Gy} \mathrm{ka}^{-1}\right)\end{array}$ & Age (ka) \\
\hline L-EV & 6 & 0.02 & 2 & .1 & 0.1 & $0.19=$ & 10 & $1.21 \pm 0.07$ & $5.1=$ \\
\hline 1229 (LL2) & $19.2=$ & $0.34 \pm 0.02$ & 3.5 & & & & $5 \pm 3$ & .06 & $t .2$ \\
\hline L-EVA 1230 (LL3) & $26.9 \pm 0.9$ & $0.69 \pm 0.04$ & $3.0 \pm 0.1$ & .1 & $0.7 \pm 0.1$ & $0.18 \pm$ & $7 \pm 3$ & .08 & $20.6 \pm 1.4$ \\
\hline L-EVA 1231 (LL4) & $22.9 \pm 1.2$ & $0.56 \pm 0.02$ & $2.7 \pm 0.1$ & $0.7 \pm 0.1$ & $0.5 \pm 0.1$ & $0.18 \pm 0.02$ & $6 \pm 3$ & $0.98 \pm 0.05$ & $23.4 \pm 1.8$ \\
\hline
\end{tabular}
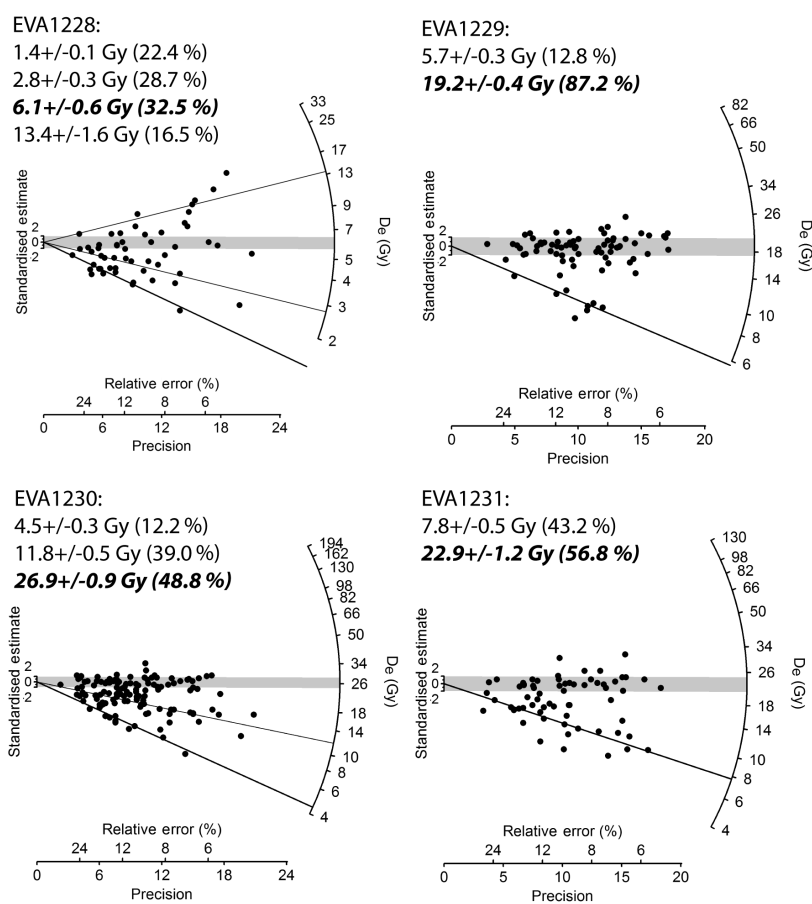

EVA1231:

$7.8+/-0.5$ Gy $(43.2 \%)$

$22.9+/-1.2$ Gy $(56.8 \%)$

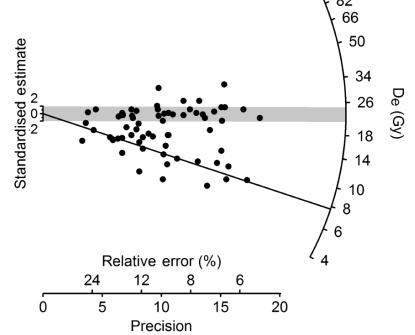

Figure 3. Equivalent-dose distributions for the LLL samples, illustrated as radial plots. The shaded populations in each case represent the dominant age peaks; the lines illustrate the other identified populations.

\section{Results}

\subsection{Geomorphology}

There are no dune or beach deposits on the western side of the lake (Fig. 1). The main geomorphic feature on the eastern side of the lake is the lunette and the low basalt ridge. The lunette comprises a north-south-oriented ridge less than $2 \mathrm{~m}$ high adjacent to the lake, a swale behind that is occupied by a small stream, and a small sand flat area that extends up to $50 \mathrm{~m}$ east of the lake shore.

The lunette on the eastern shore is composed of poorly sorted medium sand grading upwards into fine sand with accessory silt contents of 3-15\%. Particle size results and other stratigraphic information are plotted in Fig. 1, and particle size analysis curves are provided in Fig. 1 of the Supplement. GPR transects are shown in Fig. 2a and b.

On the SE margin of LLL, there is a partly infilled outlet, immediately to the west of which there is a ca. $100 \mathrm{~m}$ long, $50 \mathrm{~m}$ wide low $(<1 \mathrm{~m})$ berm. The berm is poorly to well sorted and has medium and coarse quartz-rich sand with iron-manganese, pisolithic gravel, and a silt content of 1$14 \%$.

\subsection{GPR results}

The GPR proved effective at mapping stratigraphic architecture and sub-surface character to a depth shallower than $4 \mathrm{~m}$ in the berm (Fig. 2a and b). GPR data suggest the presence of several distinct units related to changes in lake level and the development of spit/barrier and berm formations (Shan et al., 2015; Thompson et al., 2011). The berm showed strong internal stratification and features perpendicular lines with strong sigmoidal clinoforms indicating beach progradation to the west (Thompson et al., 2011) as well as low-angle sub-parallel reflectors dipping to the east suggesting basin infill via over wash processes. This package is underlain by a convex-up package of reflections that are sub-parallel with dips to the east and west. Comparison of this feature with those identified by Shan et al. (2015) suggests the complex is underlain by a spit complex. Additional information on the character of the lower units associated with the interpreted spit are unavailable due to the existing GPR data coverage.

The internal stratigraphy of the fine-grained lunette was difficult to assess with the GPR. Evidence of extensive modern bioturbation by rabbits was observed during the radar acquisition. The shallow penetration did however show weak internal characteristics commonly associated with lunette formation (Thomas and Burrough, 2016). These included eastward-dipping high-angle reflectors that are truncated on the western-facing slope, coupled with areas of parallel to sub-parallel reflections that change to steeply dipping reflections. All reflectors are laterally discontinuous and show evidence of disturbance at all depths observed, rendering the GPR data ineffective at determining genetic processes or detailed landform characteristics. 


\subsection{OSL results}

The OSL age data are summarised in Table 1 and shown with respect to stratigraphy and catchment geomorphology in Fig. 1. The three samples collected from three different locations along the lunette suggest that the entire landform was active during the LGM, between ca. 24 and $19 \mathrm{ka}$. Our samples do not extend to the base of aeolian sedimentation, and it is likely that the lunette was formed earlier than the LGM. The secondary age populations identified by FMM are all younger than the LGM phase of deposition (Fig. 3; Table S2) and suggest phases of partial reactivation or pedogenic infiltration of material into the lunette. The younger age populations from sites LL3 and LL4 in the central part of the lunette are comparable and strongly suggest contemporaneous post-depositional infiltration of younger material or partial reactivation of the lunette in the early Holocene (ca. 9-8 ka; Table S2). Sample L-EVA 1230 (LL3) exhibits a third peak centred on $11.8 \mathrm{~Gy}$ BP $(9.1 \mathrm{ka})$. The second major age population from the LL2 site in the southern part of the lunette dates to the mid-Holocene ( $5.6 \pm 0.5 \mathrm{ka}$; Table S2) and suggests spatial and temporal variability in the Holocene post-depositional pedogenesis (or reactivation) of the lunette.

The overdispersion on individual $D_{\mathrm{e}}$ results from the berm was too high (79.9\%; Table S1) to reliably define a depositional age, although the largest age population yields a midHolocene age $(5.1 \pm 0.5 \mathrm{ka}$; Table 1$)$ comparable with the reactivation of the southern part of the lunette at LL2. The minor dose populations yield ages of $11.1 \pm 1.6,2.3 \pm 0.3$ and $1.2 \pm 0.1 \mathrm{ka}$ (Table S2).

\section{Discussion}

There are two separate but related sets of geomorphic features recorded along the eastern and south-eastern margin of LLL. These are the sand and gravel berm, which is a lake beach/spit feature, and the lunette, which is an aeolian feature but tied to the shoreline. Both are supplied with sediment by wind wave processes in the lake, but the former is a sub-aqueous feature, while the lunette is an aeolian structure.

\subsection{A possible spit/barrier berm in the SE corner of the lagoon}

The most cryptic landform in the basin is the sand and gravel berm on the SE margins of LLL. The feature was identified by Gale and Haworth (2005), who interpreted it as part of a relict older lunette feature. From visual observations alone, this is a reasonable interpretation because the low berm does look like the erosional shadow of an older ridge. Our sedimentologic and GPR structural investigations, however, discount this interpretation. Based on both GPR and field observations from pits, the feature is clearly a beach berm, with numerous small wash-over structures (see Fig. 2a).

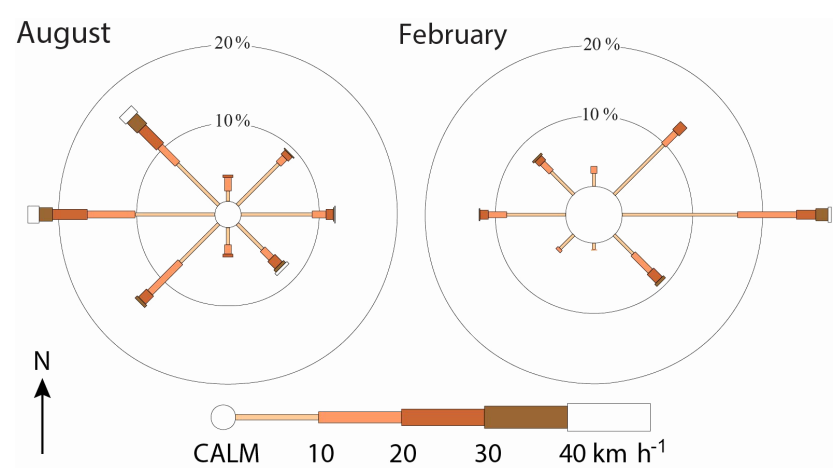

Figure 4. Rose of 09:00 wind direction vs. wind speed in $\mathrm{km} \mathrm{h}^{-1}$ at Guyra Hospital, 1332 m a.m.s.l. (Bureau of Meterology, 2014). Only winds above $\sim 22 \mathrm{kph}$ are sand-carrying (based on the 12-knot threshold of Fryberger, 1979). Sand drift potential is much stronger in winter (August) than it is in summer (February) because the relationship is a power function of the wind speed and frequency of very strong winds is much lower in summer.

The berm barrier feature is composed of pea-sized gravels within a finer sandy matrix. We assume the sandy matrix to be post-depositional because it is incompatible with the sedimentary structures and post-depositional infilling of openwork deposits is common. In addition, the contrast between locally sourced detrital basalt gravels and reworked quartz-rich sand and silt is striking. The matrix may have accumulated either through aeolian accession or through filtration of sands through the barrier during high lake stands when the berm would have acted as a permeable filter for the lake. Given the mostly coarse nature of the matrix (medium to coarse sand), we prefer the two-stage filtration hypothesis.

The pea-sized gravels are detrital. We suggest that the most likely origin for this feature is as a spit that developed from the basalt ridge on the SW edge of the lake and that the basalt gravels were moved along the shoreline by longshore drift. The barrier ultimately cut off an area to the SW of the present lake that was part of a larger, ancestral lake feature, for which we have no age constraint due to the lack of associated sedimentary deposits. The barrier post-dates the LGM as we have been provided with a radiocarbon result (R. Haworth, personal communication, 2016) from a depth of $1.5 \mathrm{~m}$ close to our LL1 sample (Beta-110588: $16200 \pm 70$ yr BP; median: 19500 cal yr BP; calibration from Stuiver and Reimer (1993) (Calib 7.1) with a Southern Hemisphere correction (SHCal13) from Hogg et al., 2013) that provides a maximum age for the barrier. The luminescence sample based on the finer matrix material at $0.5 \mathrm{~m}$ depth yielded a highly dispersed dose distribution with four age populations, which is not unexpected given our hypothesis that the matrix is post-depositional. The grains may represent the accretion of fines to the barrier during high stands in the lake in the early (ca. $11 \mathrm{ka})$, mid- (ca. $5.6 \mathrm{ka}$ ) and late Holocene (ca. 2.3, 1.2 ka). 


\subsection{Aeolian history of LLL from the lunette}

Based on the morphology, sedimentary composition, and internal structure, the feature along the eastern shoreline of LLL is clearly a composite beach and aeolian landform. The quartz-rich sands were most likely derived from the granites on the eastern side of the catchment, which deposited into the lake and were subsequently reworked onto the shoreline. Half the basin is comprised of basalt, yet there is little evidence for basalt-derived sediments in the lunette system. By contrast, the fine sediments in the depocentre of the lake basin are primarily derived from basalt. This implies that there is an effective sorting mechanism within the basin, whereby the basalt preferentially weathers to mud while the granite generates sand. Sorting by currents would transport the fines to the depocentre, while the sands would be transported towards the lake margins. The most parsimonious candidate for this latter process is wind-blown waves.

Present-day wind roses for LLL (BOM, 2014) demonstrate that there are two primary wind directions (Fig. 4), one from the east and the other from the west to north-west. These prevailing winds have strong seasonal components. Winter winds (August) are dominated by westerlies and provide the strongest and most persistent flows $(8 \%$ calm) consistent with eastward transport and deposition of sediments onto a lunette situated on the eastern shoreline of LLL. Summer winds (February) are dominated by easterlies associated with onshore circulation on the northern limb of the subtropical high-pressure cell in summer (Fig. 4). These easterly winds are on average weaker $(20 \% \mathrm{calm})$ but do include short periods of relatively high-intensity winds, which might be expected to result in sediment transport to, and deposition onto, the western side of the lake. It is curious therefore that all depositional landforms marginal to LLL are located on the east and south-east sides of the lake, with no deposition on the western shoreline. Examination of the wind roses indicates that sand-transporting winds (above $\sim 22 \mathrm{~km} \mathrm{~h}^{-1}$ : Fryberger, 1979) were more than twice as frequent $(\sim 14 \%$ vs. $\sim 5 \%)$ in August than in February and that the highest wind speeds occurred more frequently in August. This confirms that the most effective net sand-transporting wind, associated with lunette and berm formation, was from the west/north-west. The transport is most likely to have been primarily sub-aqueous, since the relatively poor sorting in the foredune indicates only a short-distance aeolian transport pathway.

In addition to the stronger drift potential there may also be a biological effect. The rush beds occurring in the shallower parts of the lake are most fully developed during the summer. Unlike much of Australia, winters are severe on the New England Tablelands due to the relatively high elevations, and seasonal die-back of the tall spike rush is observed today. New growth emerges in spring and dies off in autumn in cooler, high-altitude sites (Rajapaskse et al., 2006). Consequently, the summer peak in vegetation cover disrupts the wind fetch over the lake precisely at the same time as the easterly winds penetrate the tablelands, thereby further reducing the ability for waves to set up during the warmer months.

The luminescence ages from the lunette are coherent. All samples are dominated by grains that are LGM in age. The samples all overlap at $2 \sigma$ and produce a weighted mean age of $20.4 \pm 0.8 \mathrm{ka}$, indicating that the main phase of dune activity at LLL occurred during the late LGM. Our interpretation that the dominant sediment transport mechanism was subaqueous therefore implies that the LGM oversaw permanent, and probably full, lake conditions at LLL. Evidence from our unpublished sedimentary archives from the depocentre of the lake supports the concept of a full lake during the late LGM (ca. $19 \mathrm{ka}$ ). Specifically, the lake sediments from this time interval are an unoxidised grey clay, which contains numerous sponge spicules. In addition, pollen records from these latitudes suggest the survival of rainforest at lower elevations to the east through the LGM (e.g. Moss et al., 2013), indicating persistence of moisture availability. Our argument for the persistence, and perhaps intensification, of winter westerlies throughout the LGM at LLL is also confirmed by observations made at North Stradbroke Island some $300 \mathrm{~km}$ to the north-north-east of our site (Petherick et al., 2009; McGowan et al., 2008). North Stradbroke Island lies at the very northern edge of the westerlies zone, and the accession of fine aeolian material into a dune lake there indicates that the winter westerlies were operative at the LGM in South East Queensland at 27.20 $\mathrm{S}$ (Petherick et al., 2009; McGowan et al., 2009), just as the westerlies operate today in this region.

A secondary peak in grain ages is observed in all three lunette samples. This peak is less well defined but in all three cases relates to the early to mid-Holocene between 9 and $6 \mathrm{ka}$. Work from the lake (Woodward et al., 2011) has already demonstrated that the early Holocene was the last phase, before the modern anthropogenically modified lake, with lake full conditions as represented by extensive Eleocharis beds. Wind waves would have been effective on the lake, and we infer partial reactivation of the lunette at this time.

We note a third grain age peak in one lunette sample (EVA1230) at ca. $3 \mathrm{ka}$. This is both the weakest individual age peak and not replicated at any other site. It is possible that this represents a dune re-activation event; bioturbation; or even Aboriginal usage of the site, which has been proposed to have intensified during the late Holocene (post 4300 years; Beck et al., 2015). At this stage this event, if real, is still poorly controlled chronologically, and we do not interpret it further.

Overall, our evidence demonstrates that, at the LGM, winter westerly winds were strong enough to form the eastern shoreline lunette in a single phase, with possible later reactivation during the early Holocene. Critically, foredune activation depends as much on high water levels in the lake allowing the wave delivery of sediment to the eastern beach as it does on sand-mobilising winds (Bowler, 1983). During 
the Pleistocene, elevations above $800 \mathrm{~m}$ in the region were subject to extensive, active development of block deposits, screes, and solifluction lobes, indicating winter cooling of at least $10.5^{\circ} \mathrm{C}$ relative to present (Slee and Shulmeister, 2015). Reduced evaporation due to lower temperatures (e.g. Hesse et al., 2003) and transfer of flow from throughflow/baseflow to overland flow due to increased snow cover (Reinfelds et al., 2014) at this time are likely to have been sufficient to cause the change to a positive hydrological balance in the lake.

For the intervening periods, at least in the Holocene, the evidence (Woodward et al., 2014a) suggests that water levels were lower and/or even that the lake was ephemeral. It is highly unlikely that sand would be transported to the highstand beach during low lake levels. If the entire basin floor fully dried out, pelletised clays might be expected, and yet none are observed. There are two likely reasons for this. Firstly, this high-elevation site is unlikely to become very arid even during relatively dry phases when swampy conditions probably persisted on the basin floor. Similarly, it is unlikely that salt formation is significant in this setting, and clay pelletisation may not occur. This is similar to observations from Lake George, which also lies within a cool temperate climate setting along the Great Dividing Range (Fitzsimmons and Barrows, 2010).

In summary, these records strongly suggest that for the two intervals recorded (the LGM and early Holocene) the overall circulation conditions at LLL were very similar to the present day. This region presently lies near the northern limit of westerly penetration in winter. For the intervening periods, absence of evidence is not evidence of absence; if the winter westerly winds lay at this latitude during peak warming in the early Holocene and during the LGM, it seems reasonable to suppose that this track has been persistent over the last 25 kyr.

The track of the Australian winter westerlies during the LGM has been a source of contention for some time, with both poleward and equatorward changes argued for (e.g. Harrison and Dodson, 1993; Hesse, 1994; Shulmeister et al., 2004). One possibility is that the westerly lay north of its current track during the LGM and that the timing of the westerlies at LLL shifted seasonally. A northward shift of $\sim 3^{\circ}(350 \mathrm{~km})$ in the position of the westerly wind belt during marine isotope stage (MIS) 2 was recorded in sediments from marine cores in the Tasman Sea (Hesse, 1994). Analysis of the aeolian component of lake sediments on North Stradbroke Island at $27^{\circ} \mathrm{S}$ for the period 25-22 ka indicates dust sources in the SW Murray-Darling Basin, with a secondary component from WNW of the site (Petherick et al., 2009). These findings are consistent with either no change or a possible northward shift in the westerlies but are not consistent with the poleward contraction of the westerlies in eastern Australia at the LGM.

\section{Conclusions}

This study indicates that westerly winds activated a lunette at LLL during the LGM under the influence of high lake levels. This ridge was reactivated during high lake stands in the early to mid-Holocene. The persistence of westerly winds at this site during the LGM confirms observations from North Stradbroke Island at the northern limits of penetration of the temperate-latitude westerlies. This suggests that the overall circulation pattern in this part of eastern Australia, at the modern northern limits of westerly winter flow, remained constant during both the LGM and the early Holocene. Overall, this points to minimal change in circulation patterns over the last $25 \mathrm{kyr}$.

\section{Data availability}

Summary statistics for rainfall and temperature data from the Guyra Hospital weather station $\left(30.21^{\circ} \mathrm{S}, 151.68^{\circ} \mathrm{E} ; 1329 \mathrm{~m}\right.$ elevation) from 1981 to 2016 and for other climatic variables including wind speed and direction for the period from 1981 to 2010 (see http://www.bom.gov.au/climate/averages/ tables/cw_056229.shtml).

\section{The Supplement related to this article is available online at doi:10.5194/cp-12-1435-2016-supplement.}

Author contributions. James Shulmeister led the project, assisted with field sampling for OSL and grain size, and led the manuscript development. Justine Kemp assisted in the field with OSL sample acquisition, conducted grain size analysis, and participated in manuscript development. Kathryn E. Fitzsimmons undertook the OSL sample analysis and participated in manuscript development. Allen Gontz led the GPR acquisition and processing and assisted with OSL sampling and manuscript development.

Acknowledgements. This research was funded by Australian Research Council Discovery Grant DP110103081, "The last glaciation maximum climate conundrum and environmental responses of the Australian continent to altered climate states". We thank $\mathrm{S}$. Hesse for assistance with OSL sample preparation. R. Haworth made a radiocarbon age from underneath the sand and gravel berm available to us. C. Woodward, J. Chang, and A. Slee assisted with fieldwork. We thank all the referees for very helpful input that has improved the paper. We thank NSW National Parks and Wildlife Service for access to the site and the local farmers for retrieving our vehicle from the bottomless suckhole!

Edited by: A. Lorrey

Reviewed by: P. Hesse, W. Beck, and one anonymous referee 


\section{References}

Beck, W., Haworth, R., and Appleton, J.: Aboriginal resources change through time in New England upland wetlands, southeast Australia, Archaeol Ocean., 50, 47-57, 2015.

Bell, D. M., Hunter, J. T., and Haworth, R. J.: Montane lakes (lagoons) of the New England tablelands bioregion, Cunninghamia, 10, 475-492, 2008.

Botter-Jensen, L., Bulur, E., Duller, G. A. T., and Murray, A. S.: Advances in luminescence instrument systems, Radiat. Meas., 32, 523-528, 2000.

Bowler, J. M.: Aridity in Australia: Age, origins and expression in aeolian landforms and sediments, Earth Sci. Rev., 12, 279-310, 1971.

Bowler, J. M.: Clay Dunes: Their occurrence, formation and environmental significance, Earth Sci. Rev., 9, 315-338, doi:10.1016/0012-8252(73)90001-9, 1973.

Bowler, J. M.: Aridity in Australia: age, origins and expression in aeolian landforms and sediments, Earth Sci. Rev., 12, 279-310, 1976.

Bowler, J. M.: Lunettes as indices of hydrologic change: a review of Australian evidence, Proc. R. Soc. Victoria, 95, 147-168, 1983.

Bowler, J. M.: Spatial variability and hydrologic evolution of Australian lake basins: analogue for Pleistocene hydrologic change and evaporite formation, Palaeogeogr. Palaeoclim. Palaeoecol., 54, 21-41, 1986.

Bureau of Meteorology: Summary statistics Guyra Hospital, Climate Data Online, available at: http://www.bom.gov.au/ climate/averages/tables/cw_056229.shtml (last access: 29 February 2016), 2014.

Coenraads, R. R.: Evaluation of the natural lagoons of the Central Province, NSW - Are they sapphire-producing maars?, Explor Geophys., 20, 347-363, 1989.

Denton, G. H., Anderson, R. F., Toggweiler, J. R., Edwards, R. L., Schaefer, J. M., and Putnam, A. E.: The last glacial termination, Science, 328, 1652-1656, doi:10.1126/science.1184119, 2010.

Fitzsimmons, K. E. and Barrows, T. T.: Holocene hydrologic variability in temperate southeastern Australia: An example from Lake George, New South Wales, The Holocene, 20, 585-597, 2010.

Fitzsimmons, K. E., Stern, N., and Murray-Wallace, C. V.: Depositional history and archaeology of the central Lake Mungo lunette, Willandra Lakes, southeast Australia, J. Archaeol Sci., 41, 349364, 2014.

Fletcher, M. S. and Moreno, P. I.: Have the Southern Westerlies changed in a zonally symmetric manner over the last 14,000 years? A hemisphere-wide take on a controversial problem, Quaternary Int., 253, 32-46, 2012.

Fryberger, S. G.: Dune forms and wind regime, in: A study of global sand seas, edited by: McKee, E. D., Gov print office, Washington, USA, 137-160, 1979.

Galbraith, R. F. and Green, P. F.: Estimating the component ages in a finite mixture, Nucl. Tracks Rad. Meas., 17, 197-206, 1990.

Gale, S. J. and Haworth, R. J.: Catchment-wide soil loss from preagricultural times to the present: transport-and supply-limitation of erosion, Geomorphology, 68, 314-333, 2005.

Gale, S. J., Haworth, R. J., and Pisanu, P. C.: The 210 Pb chronology of late Holocene deposition in an eastern Australian lake basin, Quaternary Sci. Rev., 14, 395-408, 1995.
Harrison, S. P. and Dodson, J. R.: Climates of Australia and New Guinea since 18,000 yr B.P, in: Global Climates Since the Last Glacial Maximum, edited by: Wright Jr., H. E., Kutzbach, J. E., Webb III, T., Ruddiman, W. F., Street-Perrot, F. A., and Bartlein, P. J., University of Minnesota Press, Minneapolis, MN, 265-293, 1993.

Hesse, P. P.: The record of continental dust from Australia in Tasman Sea sediments, Quaternary Sci. Rev., 13, 257-272, 1994.

Hesse, P. P., Humphreys, G. S., Selkirk, P. M., Adamson, D. A., Gore, D. B., Nobes, D. C., Price, D. M., Schwenninger, J.-L., Smith, B., Tulau, M., and Hemmings, F.: Late Quaternary aeolian dunes on the presently humid Blue Mountains, Eastern Australia, Quaternary Int., 108, 13-32, 2003.

Hogg, A. G., Hua, Q., Blackwell, P. G., Buck, C. E., Guilderson, T. P., Heaton, T. J., Niu, M., Palmer, J. G., Reimer, P. J., Reimer, R. W., Turney, C. S. M., and Zimmerman, S. R. H.: SHCal13 Southern Hemisphere Calibration, 0-50,000 years cal BP, Radiocarbon, 55, 1889-1903, doi:10.2458/azu_js_rc.55.16783, 2013.

Jacobs, Z. and Roberts, R. G.: Advances in optically stimulated luminescence dating of individual grains of quartz from archeological deposits, Evol. Anthropol., 16, 210-223, 2007.

Lorrey, A. M., Vandergoes, M., Almond, P., Renwick, J., Stephens, T., Bostock, H., Mackintosh, A., Newnham, R., Williams, P. W., Ackerley, D., and Neil, H.: Palaeocirculation across New Zealand during the last glacial maximum at $\sim 21 \mathrm{ka}$, Quaternary Sci. Rev., 36, 189-213, 2012.

McGowan, H. A., Petherick, L. M., and Kamber, B. S.: Aeolian sedimentation and climate variability during the late Quaternary in southeast Queensland, Australia, Palaeogeogr. Palaeocl., 265, 171-181, 2008.

Mejdahl, V.: Thermoluminescence dating: beta-dose attenuation in quartz grains, Archaeometry, 21, 61-72, 1979.

Moss, P. T., Tibby, J., Petherick, L., McGowan, H., and Barr, C.: Late Quaternary vegetation history of North Stradbroke Island, Queensland, eastern Australia, Quaternary Sci. Rev., 74, $257-$ 272, 2013.

Murray, A. S. and Wintle, A. G.: Luminescence dating of quartz using an improved single-aliquot regenerative-dose protocol, $\mathrm{Ra}-$ diat. Meas., 32, 57-73, 2000.

Murray, A. S. and Wintle, A. G.: The single aliquot regenerative dose protocol: potential for improvements in reliability, Radiat. Meas., 37, 377-381, 2003.

Neal, A.: Ground penetrating radar and its use in sedimentology: principles, problems and progress, Earth Sci. Rev., 66, 261-330, 2004.

Ollier, C. D.: Evolutionary Geomorphology of Australia and Papua: New Guinea, T I Brit. Geog., 4, 516-539, 1979.

Petherick, L. M., McGowan, H. A., and Kamber, B. S.: Reconstructing transport pathways for late Quaternary dust from eastern Australia using the composition of trace elements of long traveled dusts, Geomorphology, 105, 67-79, 2009.

Prescott, J. R. and Hutton, J. T.: Cosmic ray contributions to dose rates for luminescence and ESR dating: Large depths and long term variations, Radiat. Meas., 23, 497-500, 1994.

Rajapakse, L., Asaeda, T., Williams, D., Roberts, J., and Manatunge, J.: Effects of water depth and litter accumulation on morpho-ecological adaptations of Eleocharis sphacelata, Chem. Ecol., 22, 47-57, 2006. 
Reinfelds, I., Swanson, E., Cohen, T., Larsen, J., and Nolan, A.: Hydrospatial assessment of streamflow yields and effects of climate change: Snowy Mountains, Australia, J. Hydrol., 512, 206-220, 2014.

Shan, X., Yu, X., Clift, P. D., Tan, C., Jin, L., Li, M., and Li, W.: The ground penetrating radar facies and architecture of a paleospit from Huangqihai Lake, North China: implications for genesis and evolution, Sediment. Geol., 323, 1-14, 2015.

Shaw, S. E. and Flood, R. H.: The New England Batholith, eastern Australia: geochemical variations in time and space, J. Geophys. Res.-Sol. Ea., 86, 10530-10544, 1981.

Shulmeister, J., Goodwin, I., Renwick, J., Harle, K., Armand, L., McGlone, M. S., Cook, E., Dodson, J., Hesse, P. P., Mayewski, P., and Curran, M.: The Southern Hemisphere westerlies in the Australasian sector over the last glacial cycle: a synthesis, Quaternary Int., 118, 23-53, 2004.

Slee, A. and Shulmeister, J.: The distribution and climatic implications of periglacial landforms in eastern Australia, J. Quaternary Sci., 30, 848-858, 2015.

Stokes, S., Ingram, S., Aitken, M. J., Sirocko, F., Anderson, R., and Leuschner, D.: Alternative chronologies for Late Quaternary (Last Interglacial-Holocene) deep sea sediments via optical dating of silt-sized quartz, Quaternary Sci. Rev., 22, 925-941, 2003.
Stuiver, M. and Reimer, P. J.: Extended ${ }^{14} \mathrm{C}$ data base and revised CALIB $3.0{ }^{14} \mathrm{C}$ age calibration program, Radiocarbon, 35, 215230, 1993.

Thomas, D. S. G. and Burrough, S. L.: Luminescence-based chronologies in southern Africa: analysis and interpretation of dune database records across the subcontinent, Quaternary Int., 1-16, in press, 2016.

Thompson, T. A., Lepper, K., Endres, A. L., Johnston, J. W., Baedke, S. J., Argyilan, E. P., Booth, R. K., and Wilcox, D. A.: Mid Holocene lake levels and shoreline behaviour during the Nipissing phase of the upper Great Lakes at Alpena, Michigan, USA, J. Great Lake Res., 37, 567-576, 2011.

Woodward, C., Chang, J., Zawadzki, A., Shulmeister, J., Haworth, R., Collecutt, S., and Jacobsen, G.: Evidence against early nineteenth century major European induced environmental impacts by illegal settlers in the New England Tablelands, south eastern Australia, Quaternary Sci. Rev., 30, 3743-3747, 2011.

Woodward, C., Shulmeister, J., Bell, D., Haworth, R., Jacobsen, G., and Zawadzki, A.: A Holocene record of climate and hydrological changes from Little Llangothlin Lagoon, south eastern Australia, The Holocene, 24, 1665-1674, 2014a.

Woodward, C., Shulmeister, J., Larsen, J., Jacobsen, G. E., and Zawadzki, A.: The hydrological legacy of deforestation on global wetlands, Science, 346, 844-847, 2014 b. 